\title{
Evidence-based clinical update: Which local anesthetic drug for pediatric caudal block provides optimal efficacy with the fewest side effects? Mise à jour des données cliniques fondée sur des données
probantes: Pour une anesthésie caudale chez l'enfant, quel
anesthésique local est le plus efficace et entraîne le moins d'effets
indésirables?
}

\author{
Elisabeth F. A. Dobereiner, MD - Robin G. Cox, MBBS • \\ Alastair Ewen, MB ChB - David R. Lardner, MB ChB
}

Received: 17 June 2010/Accepted: 1 September 2010/Published online: 16 September 2010

(C) Canadian Anesthesiologists' Society 2010

\begin{abstract}
Purpose The purpose of this evidence-based clinical update is to identify the best evidence when selecting a long-acting local anesthetic agent for single-shot pediatric caudal anesthesia in children.

Methods A structured literature search was conducted using PubMed and Medline (OVID) using the terms "caudal" and combinations of at least two of "bupivacaine", "ropivacaine", and "levobupivacaine". The search limits included "randomized controlled trials" (RCTs), "metaanalysis", "evidence-based reviews" or "reviews", "human", and "all child: 0-18 yr". Seventeen RCTs were identified that concerned single-shot pediatric caudal anesthesia with at least two of the three drugs in question. Data were extracted for the areas of clinical efficacy and side effects. Study findings were assigned levels of evidence, and grades of recommendation were made according to Centre for Evidence-Based Medicine criteria.

Results The three drugs investigated were found to be equivalent in terms of efficacy. Evidence showed bupivacaine with the highest incidence of motor block and ropivacaine with the lowest. Adverse effects were rare and unrelated to the choice of drug. There were no serious adverse events.
\end{abstract}

E. F. A. Dobereiner, MD · R. G. Cox, MBBS $(\bowtie)$.

A. Ewen, MB ChB - D. R. Lardner, MB ChB

Department of Anesthesiology, Alberta Children's Hospital,

University of Calgary, 2888 Shaganappi Trail N.W, Calgary,

AB T3B 6A8, Canada

e-mail: robin.cox@albertahealthservices.ca
Conclusion None of the three agents was shown to be superior in terms of efficacy. Bupivacaine is preferred if motor block is desired, ropivacaine is preferred if motor block is to be minimized. Adverse effects in human studies are rare, mild, and unrelated to the choice of drug.

Despite encountering the absence of serious adverse events in each of the studies reviewed, it is noted that animal studies suggest a safer profile with ropivacaine or levobupivacaine than with bupivacaine.

\section{Résumé}

Objectif Cette mise à jour des données cliniques fondée sur des données probantes a pour but d'identifier les données les plus concluantes permettant de sélectionner un anesthésique local à action prolongée dans le cas d'une anesthésie caudale avec une seule injection chez l'enfant. Méthode Une recherche documentaire méthodique a été effectuée sur PubMed et Medline (OVID) en utilisant le terme «caudal» et différentes combinaisons comprenant au moins deux des termes suivants: «bupivacaïe», «ropivacaïne» et «lévobupivacaïne». Les paramètres de recherche incluaient: «études randomisées contrôlées», «méta-analyse», «articles de synthèse fondés sur des données probantes» ou «articles de synthèse», «humain»et«tous les enfants: 0 à 18 ans». On a identifié 17 études cliniques randomisées portant sur l'anesthésie caudale avec une seule injection chez l'enfant dans lesquelles on utilisait au moins deux des trois médicaments concernés. Les données relatives à l'efficacité clinique et aux effets secondaires ont été retenues. On a ensuite attribué différents niveaux de corroboration aux résultats des essais, et des grades de 
recommandation ont été accordés en fonction des exigences du Centre for Evidence-Based Medicine.

Résultats Les trois médicaments étudiés ont été jugés équivalents sur le plan de l'efficacité. Les résultats montrent que la bupivacaïne présente l'incidence la plus élevée de bloc moteur et que la ropivacaïne présente l'incidence la moins elevée. Les effets indésirables sont rares et sans rapport avec le choix du médicament. Aucun événement indésirable grave n'a été observé.

Conclusion Aucun des trois agents n'a été jugé supérieur sur le plan de l'efficacité. On privilégie la bupivacaïne pour favoriser le bloc moteur et la ropivacaïne si l'on cherche à en minimiser les effets. Dans le cadre d'essais effectués chez l'humain, les effets indésirables sont rares, légers et sans rapport avec le choix du médicament.

Single-shot caudal anesthesia is an established method of providing perioperative analgesia that is commonly performed in children undergoing penile surgery or inguinal hernia repair. There are several different local anesthetic agents available for this regional block. Bupivacaine, levobupivacaine, and ropivacaine are the long-acting agents most commonly encountered. All three agents have been used successfully for pediatric caudal anesthesia, but there may be some differences in their relative potency, efficacy, side effects, and toxicity. In this evidence-based clinical update, structured evidence-based methodology is used to compare the relative efficacy (onset time, quality of intraoperative analgesia, and duration of postoperative analgesia), side effects (including motor block), and toxicity (cardiac or neurological) of these three agents. It is important to appreciate the relative potency of bupivacaine, levobupivacaine, and ropivacaine in order to make a fair comparison of these three agents.

To provide an effective caudal block in children, local anesthetic agents must often be given at doses and volumes that approach the maximum recommended to avoid toxicity. Consequently, the balance between effectiveness, side effects, and toxicity becomes crucial when selecting one of these agents. After considering the findings of this review, anesthesiologists might be better able to make an informed decision regarding choice of local anesthetic for single-shot pediatric caudal anesthesia.

\section{Clinical question}

You are asked to provide anesthesia for a healthy threeyear-old boy requiring bilateral inguinal hernia repair. You plan general anesthesia (sevoflurane, laryngeal mask), supplemented by a single-shot caudal block. You have three long-acting local anesthetics from which to choose, i.e., bupivacaine, levobupivacaine, or ropivacaine. You question which drug will provide optimal efficacy with the lowest incidence of side effects and toxicity.

\section{Methods}

A structured electronic literature search was conducted, using both PubMed and Medline (OVID). Search terms included "caudal" and combinations of at least two of "bupivacaine", "ropivacaine", and "levobupivacaine" (four separate searches). Search limits included "human" and "all child: 0-18 yr". In the case of PubMed, publication limits were defined as "randomized controlled trials" (RCTs), "meta-analysis", or "reviews". With Medline (OVID), the publication limits were defined as "randomized controlled trials", "evidence-based reviews", or "reviews". No limit was placed on publication date; the searches were completed in August 2010. A total of 28 references were obtained, and the abstracts were reviewed by two of the authors (E.F.A.M. and R.G.C.). Studies were identified that fit the criterion of a randomized controlled trial of at least two of the three local anesthetic agents when used for single-shot caudal anesthesia in children. Seventeen such RCTs were reviewed in detail using a structured methodology. ${ }^{1-17}$ Two review articles were also identified. ${ }^{18,19}$ The reference lists for all of these 19 publications were reviewed to identify any further RCTs that may have been missed with the initial search strategy; no such study was found. One meta-analysis was found using these search limits, but it did not specifically address single-shot caudal anesthesia in children. A separate search of the Cochrane Library did not identify any reviews that addressed our clinical question.

Each RCT was graded independently for quality using the Jadad score ${ }^{20}$ and Centre for Evidence-Based Medicine $(\mathrm{CEBM})^{21}$ criteria (Appendices 1 and 2). The Jadad score only evaluates randomization, blinding, and handling of withdrawals. Scoring was performed independently by three experienced pediatric anesthesiologists (R.G.C., D.R.L., and A.E.). These reviewers not only took the Jadad score into account but they also used criteria such as allocation concealment, appropriateness of the statistical tests used, confidence intervals, quality of the sample size calculation, standardization of anesthetic technique, and validity of the pain score (if used). The three reviewers discussed any disagreement between the Jadad and CEBM scores and arrived at a consensus score. The papers were reviewed further by all of the authors, and data for anesthesia outcomes were extracted in the following domains: 


\section{Relative efficacy}
a) Onset time
b) Intraoperative quality
c) Duration of postoperative analgesia

\section{Side effects}
a) Motor block
b) Others

Characteristics of study design were documented, including the concentration and dose of drugs used, the number of subjects, age ranges, and surgical procedures performed. Finally, a review of the evidence was undertaken for the outcomes of interest, taking into account the quality of the studies involved. Recommendations were then made according to CEBM criteria (Appendix 2).

\section{Comment on relative potency}

Evaluating the efficacy and side effects of the local anesthetic agents must be viewed in the context of their relative potency. There is some uncertainty about the relative potency of these three drugs when used for single-shot pediatric caudal anesthesia. In labour, there appears to be a potency hierarchy of bupivacaine $>$ levobupivacaine $>$ ropivacaine, both with intrathecal ${ }^{22}$ and epidural $^{23,24}$ administration. With neonatal spinal anesthesia, bupivacaine appears more potent than ropivacaine or levobupivacaine, but the difference is less marked at the effective dose (ED) 95 than at the $\mathrm{ED}_{50} \cdot{ }^{25}$ In the case of pediatric caudal anesthesia, levobupivacaine and ropivacaine have been shown to have a similar potency. ${ }^{26}$ The conclusion of an excellent review by Casati pointed to slight differences in anesthetic potency among the three agents, with bupivacaine $>$ levobupivacaine $>$ ropivacaine. ${ }^{27}$ This would give bupivacaine a slight advantage in terms of efficacy, if comparing identical doses of these drugs. Eleven of the studies in this review compared only identical concentrations and doses of the drugs (Table 1). The other six studies either included different concentrations or involved more than one concentration of the same drug. Overall, it appears that most of the studies (with two notable exceptions) included in this evidence-based clinical update compared "nearly" equipotent doses of the drugs. ${ }^{5,17}$ This then represents a slight weakness in the methodology of most of the studies reviewed.

\section{Review of current best evidence}

The characteristics of the 17 RCTs reviewed are summarized in Table 1. Of note, only four of these studies were

Table 1 Summary of study characteristics

\begin{tabular}{|c|c|c|c|c|c|c|c|}
\hline Ref & Bup \% & Lev \% & Rop \% & Dose & $n$ & Age (yr) & Surgery \\
\hline 1 & 0.2 & 0.2 & 0.2 & $1 \mathrm{~mL} \cdot \mathrm{kg}^{-1}$ & 182 & $1-7$ & hernia, orchidopexy \\
\hline 2 & 0.25 & 0.25 & 0.25 & $0.5-1 \mathrm{~mL} \cdot \mathrm{kg}^{-1}$ & 99 & $6 \mathrm{~m}-10 \mathrm{yr}$ & hernia, orchidopexy, penile \\
\hline 3 & & 0.25 & 0.25 & $1 \mathrm{~mL} \cdot \mathrm{kg}^{-1}$ & 60 & $2-6$ & hernia, orchidopexy, penile \\
\hline 4 & 0.25 & 0.25 & 0.2 & $1 \mathrm{~mL} \cdot \mathrm{kg}^{-1}$ & 60 & $1-7$ & hernia, orchidopexy, penile \\
\hline 5 & 0.2 & & $0.1 / 0.2$ & $1 \mathrm{~mL} \cdot \mathrm{kg}^{-1}$ & 30 & $7 \mathrm{~m}-7 \mathrm{yr}$ & hernia, orchidopexy, penile \\
\hline 6 & 0.25 & & 0.25 & $1 \mathrm{~mL} \cdot \mathrm{kg}^{-1}$ & 75 & $1-10$ & hernia, orchidopexy, penile \\
\hline 7 & 0.25 & & 0.25 & $1 \mathrm{~mL} \cdot \mathrm{kg}^{-1}$ & 80 & $2-5$ & unilateral hernia \\
\hline 8 & 0.25 & & 0.2 & $1 \mathrm{~mL} \cdot \mathrm{kg}^{-1}$ & 245 & $1-10$ & hernia, orchidopexy, penile \\
\hline 9 & 0.375 & & 0.375 & $1 \mathrm{~mL} \cdot \mathrm{kg}^{-1}$ & 60 & $3-6$ & orchidopexy \\
\hline 10 & 0.25 & 0.25 & & $1 \mathrm{~mL} \cdot \mathrm{kg}^{-1}$ & 307 & $1 \mathrm{~m}-10 \mathrm{yr}$ & hernia, orchidopexy, penile \\
\hline 11 & 0.2 & 0.2 & 0.2 & $1 \mathrm{~mL} \cdot \mathrm{kg}^{-1}$ & 86 & $1-7$ & hernia, orchidopexy \\
\hline 12 & & 0.2 & 0.2 & $1 \mathrm{~mL} \cdot \mathrm{kg}^{-1}$ & 60 & $1-7$ & hernia, orchidopexy, penile \\
\hline 13 & 0.25 & & 0.2 & $2 \mathrm{mg} \cdot \mathrm{kg}^{-1}$ & 40 & $1-9$ & hernia, orchidopexy, penile \\
\hline 14 & 0.25 & & 0.25 & $0.75 \mathrm{~mL} \cdot \mathrm{kg}^{-1}$ & 40 & $2-12$ & hernia, circumcision \\
\hline \multirow[t]{5}{*}{15} & 0.25 & & 0.25 & Bup $3.9 \mathrm{mg} \cdot \mathrm{kg}^{-1}$ & 50 & $2-8$ & lower abdominal, urology, lower extremity \\
\hline & & & & Rop $3.6 \mathrm{mg} \cdot \mathrm{kg}^{-1}$ & & & \\
\hline & & & 0.32 & $4.1 \mathrm{mg} \cdot \mathrm{kg}^{-1}$ & & & \\
\hline & & & 0.4 & $5.1 \mathrm{mg} \cdot \mathrm{kg}^{-1}$ & & & \\
\hline & & & 0.5 & $6.5 \mathrm{mg} \cdot \mathrm{kg}^{-1}$ & & & \\
\hline 16 & 0.2 & & 0.2 & $1 \mathrm{~mL} \cdot \mathrm{kg}^{-1}$ & 20 & $1-7$ & hypospadius \\
\hline 17 & 0.25 & & $0.25 / 0.5$ & $0.75 \mathrm{~mL} \cdot \mathrm{kg}^{-1}$ & 56 & $1.5-7$ & hernia \\
\hline
\end{tabular}

Ref $=$ reference; Bup = bupivacaine; Lev = levobupivacaine; Rop = ropivacaine; $m=$ month 
found to be of high quality (CEBM 1b), and only three had a Jadad Score of 5/5 (Table 2). Several studies had small sample sizes, and sample size calculations were not performed in all cases. Only four studies compared all three drugs. Fifteen studies evaluated bupivacaine, seven evaluated levobupivacaine, and sixteen evaluated ropivacaine; this may reflect the fact that levobupivacaine is less widely available than the other two drugs. Although most comparisons involved "nearly" equipotent doses of the agents, some studies included a group with an unusually low concentration (e.g., $0.1 \%$ ropivacaine) $)^{5}$ or an unusually high concentration (e.g., $0.5 \%$ ropivacaine) ${ }^{17}$ of drug. Most studies included a pain score in the postoperative period as an outcome finding and/or as a trigger for the administration of rescue analgesia. Remarkably, there were ten different scores used in this series (Appendix 3), mostly objective/behavioural, which raises questions as to the comparability of pain data among the studies.

The principal findings of the 17 studies are summarized in Table 2, together with their Jadad Scores and CEBM ratings. The findings are discussed in relation to relative efficacy and side effects.

\section{Relative efficacy}

In nine studies that examined onset time to surgical anesthesia, seven showed no difference among the three agents. One study ${ }^{1}$ showed that levobupivacaine had a slower onset time compared with bupivacaine or ropivacaine; however, the difference was not clinically important. Another study ${ }^{13}$ showed that bupivacaine had a slower onset time compared with ropivacaine, but again, the difference was not clinically important.

Fourteen studies evaluated the quality of intraoperative anesthesia. Five of these studies based the assessment on the need for additional analgesia, typically fentanyl. One of these studies ${ }^{11}$ showed a difference in the need for intraoperative fentanyl, with ropivacaine requiring more intraoperative analgesia than either of the other agents. Another study ${ }^{5}$ showed that ropivacaine was associated with more intraoperative fentanyl requirement, but only with a $0.1 \%$ concentration. In four studies, intraoperative analgesia was evaluated by hemodynamic measures, and none of these showed a difference among the agents. Seven studies made general statements as to intraoperative efficacy, such as "all blocks were clinically successful"; no difference among the agents was identified in these qualitative assessments. In summary, only one study suggested a difference in intraoperative quality, ${ }^{11}$ with the other thirteen studies showing no difference among the three drugs.

Duration of postoperative analgesia was evaluated in all 17 studies. Thirteen studies showed no difference in the duration; four studies showed a difference. Of these four, the first study ${ }^{2}$ showed a longer duration of analgesia with bupivacaine compared with levobupivacaine or ropivacaine, as judged by Children's and Infant's Postoperative Pain Scale score and the need for analgesia. Somewhat predictably, the second study ${ }^{5}$ showed a shorter duration of postoperative analgesia with $0.1 \%$ ropivacaine compared with $0.2 \%$ ropivacaine or bupivacaine. A third study comparing bupivacaine with ropivacaine showed a longer duration with ropivacaine, evidenced by the need for, and time of, first analgesia. ${ }^{13}$ Unsurprisingly, a fourth study showed that $0.5 \%$ ropivacaine had a longer duration than $0.25 \%$ ropivacaine or bupivacaine. ${ }^{17}$ In essence, only two studies showed a difference in duration when "nearly" equipotent doses of drug were used; one showed a longer duration with bupivacaine, ${ }^{2}$ and one showed a longer duration with ropivacaine. ${ }^{13}$

\section{Side effects}

Motor block was evaluated in 16 of the studies. Eight studies showed no difference in motor block. Two of the other eight studies showed that bupivacaine caused more motor block than levobupivacaine or ropivacaine, ${ }^{1,2}$ and four showed that bupivacaine caused more motor block than ropivacaine. ${ }^{4,5,7,9}$ Two studies showed motor block in only one subject, one with $0.2 \%$ bupivacaine ${ }^{16}$ and one with $0.5 \%$ ropivacaine. ${ }^{17}$ It would appear from these data that bupivacaine has a greater tendency to cause motor block than ropivacaine, and levobupivacaine lies somewhere between the two in this regard. In general, when motor block did occur, it tended to be short-lived and not associated with complete paralysis.

Adverse events or complications were reported in 16 studies; however, there were no serious adverse events reported (e.g., cardiac or neurological toxicity) in any subject studied. Postoperative nausea and vomiting was reported in four studies; no difference was shown among the agents. Six studies reported specifically on hemodynamic changes, with four subjects overall showing selflimited sinus bradycardia, two with bupivacaine $e^{2,11}$ and one each with levobupivacaine ${ }^{11}$ and ropivacaine. ${ }^{11}$ Seven studies reported in general terms only, such as "no apparent side effects".

Given the very low incidence of serious toxicity associated with single-shot caudal anesthesia in children, it is not surprising that none of these relatively small human studies demonstrated a difference among the three agents in terms of cardiac or neurologic toxicity. Animal research does exist, however, that points to a safer profile of ropivacaine and levobupivacaine compared with bupivacaine. $^{28,29}$ 


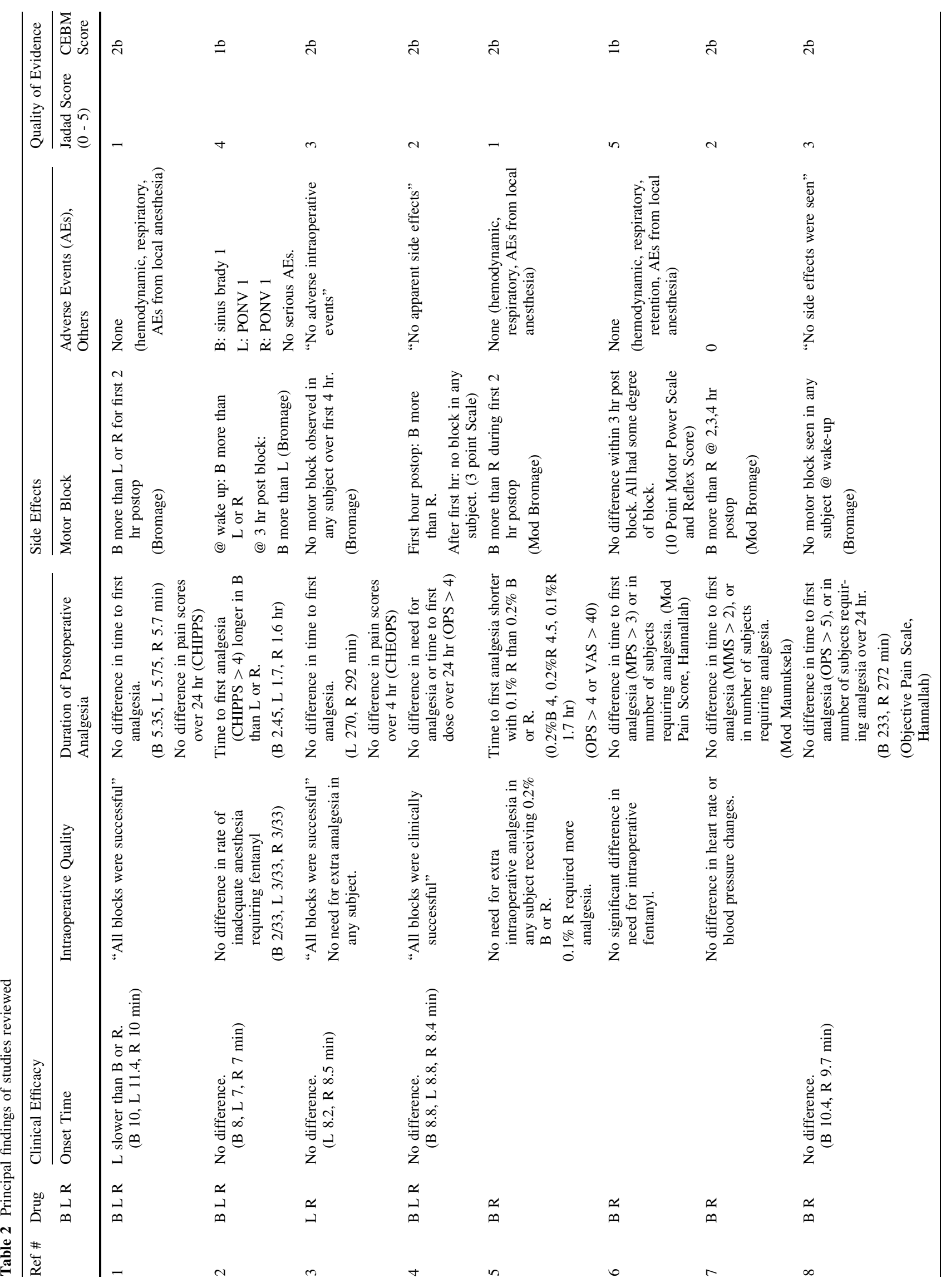




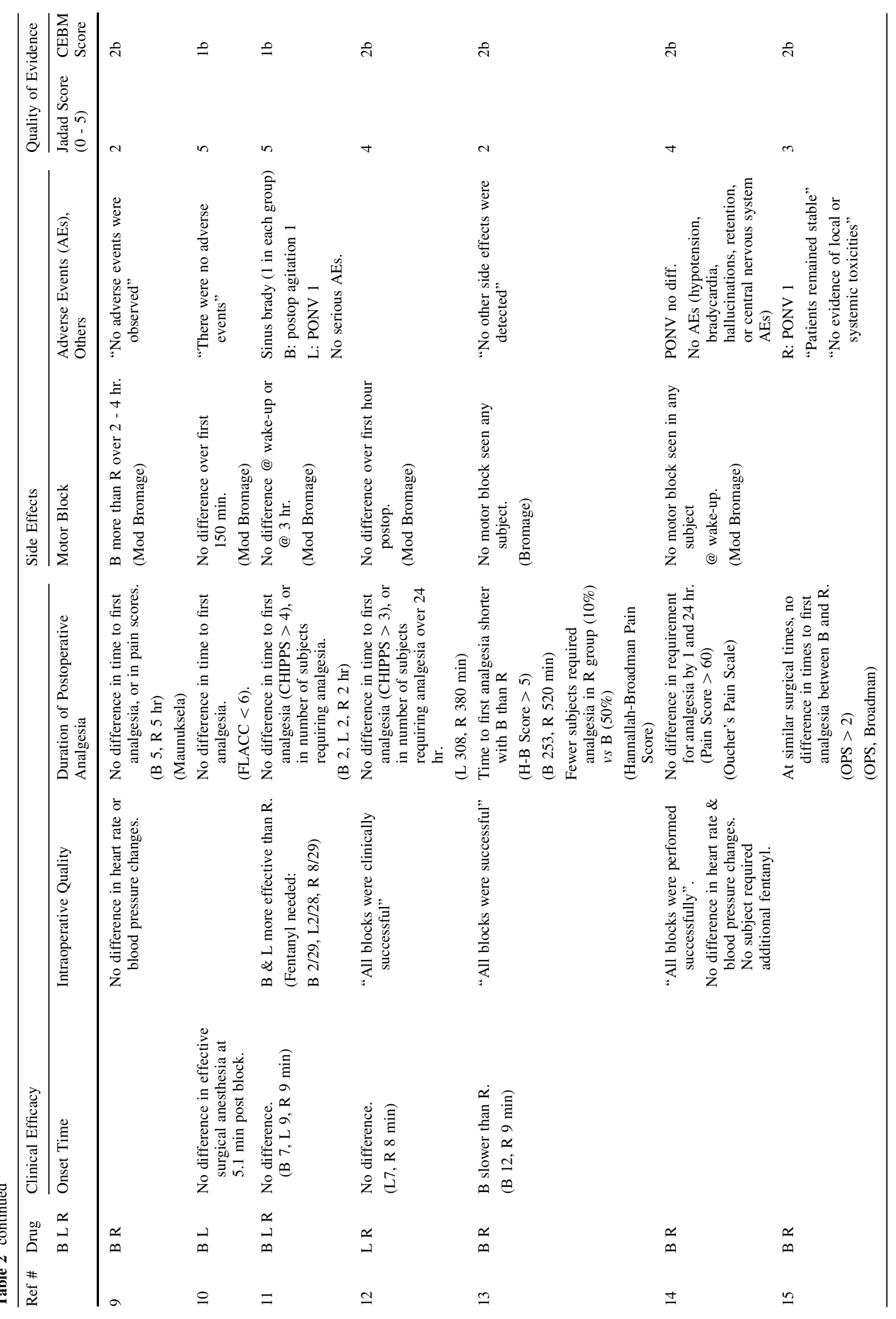




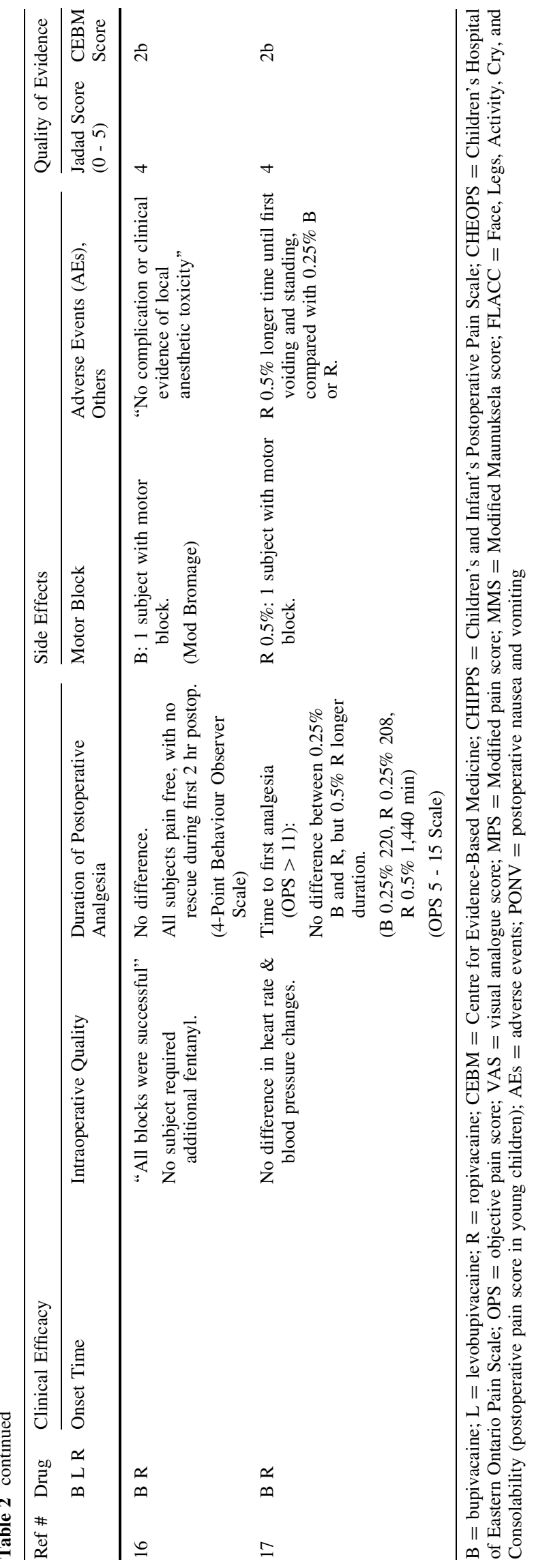

\section{Conclusions}

There is no evidence to suggest that any one of bupivacaine, levobupivacaine, or ropivacaine is preferable over the other(s) in terms of clinical efficacy when used for single-shot caudal anesthesia in children. Adverse events appear to be rare, minor in nature, and comparable in incidence among the three agents. Bupivacaine may be the drug of choice if motor block is desired; when motor block is to be minimized, ropivacaine may be the preferred option. The theoretical increased safety profile of levobupivacaine and ropivacaine, evidenced by animal studies, may be a consideration when selecting a local anesthetic agent. It is important to note that the studies included in this review did not address additives (e.g., ketamine, clonidine, or opiates), caudal anesthesia in the neonate, continuous epidural infusions, or other forms of nerve block.

\section{Recommendations}

1. The choice of a long-acting local anesthetic for singleshot pediatric anesthesia in children includes bupivacaine, levobupivacaine, and ropivacaine, with no agent being clearly superior in terms of efficacy or side effects. (Grade B recommendation);

2. Bupivacaine is preferred if motor block is desirable; ropivacaine if motor block is to be minimized. (Grade B recommendation);

3. Levobupivacaine and ropivacaine show less toxicity in animal studies compared with bupivacaine. This finding might be considered when making the choice of agent. (Grade D recommendation).

Conflict of interest No funding sources or conflicts of interest to declare.

\section{Appendix 1 Jadad score \\ Please read the article and try to answer the following questions:}

1. Was the study described as randomized (this includes the use of words such as randomly, random, and randomization)?

2. Was the study described as double-blind?

3. Was there a description of withdrawals and dropouts?

\section{Scoring the items:}

Give a score of either 1 point for each "yes" or 0 points for each "no". There are no in-between marks. 


\section{Give 1 additional point:}

If for question 1 , the method to generate the randomization sequence was described and appropriate (e.g., table of random numbers, computer-generated, etc.) and/or;

If for question 2, the method of double-blinding was described and appropriate (e.g., identical placebo, active placebo, dummy, etc.).

\section{Deduct 1 point:}

If for question 1 , the method to generate the randomization sequence was described but was inappropriate (e.g., patients were allocated alternately or according to date of birth, hospital number, etc.) and/or;

If for question 2, the study was described as double-blind but the method of blinding was inappropriate (e.g., comparison of tablet $v s$ injection with no double dummy).

\section{Appendix 2 Centre for Evidence-Based Medicine criteria}

Levels of evidence for studies concerning therapy or harm

1a Systematic Review of randomized controlled trials (RCTs) (with homogeneity)

1b Individual RCT (with narrow confidence intervals)

1c All or none study 2a Systematic review of cohort studies (with homogeneity)

$2 \mathrm{~b}$ Individual cohort study or poor quality RCT

2c Outcomes research or ecological survey

3a Systematic review of case control studies (with homogeneity)

3b Individual case-control study

4 Case-series, poor quality cohort study or poor quality case-control study

5 Expert opinion without explicit critical appraisal, or based on physiology, bench research or "first principles"

Grades of recommendation

A Consistent level 1 studies

B Consistent level 2 or 3 studies

Extrapolations from level 1 studies

C Level 4 studies

Extrapolations from level 2 or 3 studies

D Level 5 evidence

Troublingly inconsistent or inconclusive studies of any level

Appendix 3 Pain scores

\begin{tabular}{|c|c|c|c|c|c|}
\hline Name & Abbrev. & Range & Type & Reference & EBCU Study \# \\
\hline $\begin{array}{l}\text { Children's and Infant's Postoperative } \\
\text { Pain Scale }\end{array}$ & CHIPPS & $5-15$ & Objective & Anaesthetist 1990; 39: 593 & $1,2,11,12,14,17$ \\
\hline $\begin{array}{l}\text { Children's Hospital of Eastern } \\
\text { Ontario Pain Scale }\end{array}$ & CHEOPS & $4-13$ & Objective & $\begin{array}{l}\text { Advances in pain research and therapy. } \\
\text { Raven Press 1985: } 395\end{array}$ & 3 \\
\hline Objective Pain Score (Broadman) & OPS (Broadman) & $0-10$ & Objective & Anesthesiology 1987; 67: 399 & 4,15 \\
\hline Objective Pain Score (Hannallah) & OPS (Hannallah) & $0-12$ & $\begin{array}{l}\text { Objective } \pm \\
\text { Subjective }\end{array}$ & $\begin{array}{l}\text { Anesthesiology } \\
\text { 1987; 66: } 832\end{array}$ & $5,6,8,13$ \\
\hline Visual Analogue Score & VAS & $0-100$ & Subjective & Res Nurs Health 1990; 13: 227 & 5 \\
\hline Maunuksela Score & & $0-9$ & Objective & Clin Pharmacol Ther 1987; 42: 137 & 9 \\
\hline $\begin{array}{l}\text { Maunuksela Score } \\
\text { (Nakanne modification) }\end{array}$ & & $0-10$ & Objective & Br J Anaesth 1997; 78: 24 & 7 \\
\hline FLACC Score & FLACC & $0-10$ & Objective & Pediatr Nurs 1997; 23: 293 & 10 \\
\hline Oucher's Pain Scale & & $0-100$ & Objective & Pediatr Clin North Am 1989: 36: 837 & 14 \\
\hline Four Point Behaviour Observer Scale & & $1-4$ & Objective & $\begin{array}{l}\text { Acta Anaesthesiol Scand 1999; } \\
\text { 43: } 1099\end{array}$ & 16 \\
\hline
\end{tabular}

EBCU = evidence-based clinical update; FLACC = Face, Legs, Activity, Cry, and Consolability (postoperative pain score in young children) 


\section{References}

1. Breschan $C$, Jost $R$, Krumpholz $R$, et al. A prospective study comparing the analgesic efficacy of levobupivacaine, ropivacaine and bupivacaine in pediatric patients undergoing caudal blockade. Paediatr Anaesth 2005; 15: 301-6.

2. Locatelli B, Ingelmo $P$, Sonzogni $V$, et al. Randomized, doubleblind, phase III, controlled trial comparing levobupivacaine $0.25 \%$, ropivacaine $0.25 \%$ and bupivacaine $0.25 \%$ by the caudal route in children. Br J Anaesth 2005; 94: 366-71.

3. Astuto $M$, Disma $N$, Arena $C$. Levobupivacaine $0.25 \%$ compared with ropivacaine $0.25 \%$ by the caudal route in children. Eur J Anaesthesiol 2003; 20: 826-30.

4. Ivani G, DeNegri P, Conio A, et al. Comparison of racemic bupivacaine, ropivacaine, and levo-bupivacaine for pediatric caudal anesthesia: effects on postoperative analgesia and motor block. Reg Anesth Pain Med 2002; 27: 157-61.

5. Luz G, Innerhofer P, Haussler B, Oswald E, Salner E, Sparr H. Comparison of ropivacaine $0.1 \%$ and $0.2 \%$ with bupivacaine $0.2 \%$ for single-shot caudal anaesthesia in children. Paediatr Anaesth 2000; 10: 499-504.

6. Khalil S, Campos C, Farag AM, Vije H, Ritchey M, Chuang A. Caudal block in children: ropivacaine compared with bupivacaine. Anesthesiology 1999; 91: 1279-84.

7. Da Conceicao MJ, Coelho L, Khalil M. Ropivacaine $0.25 \%$ compared with bupivacaine $0.25 \%$ by the caudal route. Paediatr Anaesth 1999; 9: 229-33.

8. Ivani $G$, Lampugnani $E$, Torre $M$, et al. Comparison of ropivacaine with bupivacaine for paediatric caudal block. Br J Anaesth 1998; 81: 247-8.

9. Da Conceicao MJ, Coelho L. Caudal anaesthesia with $0.375 \%$ ropivacaine or $0.375 \%$ bupivacaine in paediatric patients. $\mathrm{Br} \mathbf{J}$ Anaesth 1998; 80: 507-8.

10. Frawley GP, Downie S, Huang GH. Levobupivacaine caudal anesthesia in children: a randomized double-blind comparison with bupivacaine. Paediatr Anaesth 2006; 16: 754-60.

11. Ingelmo PM, Locatelli BG, Sonzogni V, et al. Caudal $0.2 \%$ ropivacaine is less effective during surgery than $0.2 \%$ levobupivacaine and $0.2 \%$ bupivacaine: a double-blind, randomized, controlled trial. Paediatr Anaesth 2006; 16: 955-61.

12. Ivani $G$, De Negri $P$, Lonnqvist PA, et al. Caudal anesthesia for minor pediatric surgery: a prospective randomized comparison of ropivacaine $0.2 \%$ vs levobupivacaine $0.2 \%$. Paediatr Anaesth 2005; 15: 491-4.

13. Ivani $G$, Mereto $N$, Lampugnani E, et al. Ropivacaine in paediatric surgery: preliminary results. Paediatr Anaesth 1998; 8: 127-9.

14. Akbas M, Titiz TA, Ertugrul F, Akbas H, Melikoglu M. Comparison of the effect of ketamine added to bupivacaine and ropivacaine, on stress hormone levels and the duration of caudal analgesia. Acta Anaesthesiol Scand 2005; 49: 1520-6.
15. Aguirre-Garay FT, García R, Nava-Ocampo AA. Dose-response of ropivacaine administered caudally to children undergoing surgical procedures under sedation with midazolam. Clin Exp Pharmacol Physiol 2004; 31: 462-5.

16. Karmakar MK, Aun CS, Wong EL, Wong AS, Chan SK, Yeung $C K$. Ropivacaine undergoes slower systemic absorption from the caudal epidural space in children than bupivacaine. Anesth Analg 2002; 94: 259-65.

17. Koinig H, Krenn CG, Glaser C, et al. The dose-response of caudal ropivacaine in children. Anesthesiology 1999; 90: 1339-44.

18. Marhofer P, Koinig H, Kapral S. The choice of drugs for caudal anaesthesia in children. An overview (German). Anaesthesist 2003; 52: 55-67.

19. Ingelmo PM, Fumagalli R. Central blocks with levobupivacaina in children. Minerva Anestesiol 2005; 71: 339-45.

20. Jadad AR, Moore RA, Carroll D, et al. Assessing the quality of reports of randomized clinical trials: is blinding necessary? Control Clin Trials 1996; 17: 1-12.

21. Centre for Evidence Based Medicine. Evidence 2010 - Transforming Healthcare. Available from URL: http://www.cebm.net (accessed August, 2010)

22. Camorcia M, Capogna G, Columb MO. Minimum local analgesic doses of ropivacaine, levobupivacaine, and bupivacaine for intrathecal labor analgesia. Anesthesiology 2005; 102: 646-50.

23. Lyons $G$, Columb M, Wilson RC, Johnson RV. Epidural pain relief in labour: potencies of levobupivacaine and racemic bupivacaine. Br J Anaesth 1998; 81: 899-901.

24. Capogna $G$, Celleno D, Fusco P, Lyons $G$, Columb M. Relative potencies of bupivacaine and ropivacaine for analgesia in labour. Br J Anaesth 1999; 82: 371-3.

25. Frawley $G$, Smith $K R$, Ingelmo $P$. Relative potencies of bupivacaine, levobupivacaine, and ropivacaine for neonatal spinal anaesthesia. Br J Anaesth 2009; 103: 731-8.

26. Ingelmo $P$, Frawley $G$, Astuto $M$, et al. Relative analgesic potencies of levobupivacaine and ropivacaine for caudal anesthesia in children. Anesth Analg 2009; 108: 805-13.

27. Casati A, Putzu M. Bupivacaine, levobupivacaine and ropivacaine: are they clinically different? Best Pract Res Clin Anaesthesiol 2005; 19: 247-68.

28. Morrison SG, Dominguez JJ, Frascarolo P, Reiz S. A comparison of the electrocardiographic cardiotoxic effects of racemic bupivacaine, levobupivacaine, and ropivacaine in anesthetized swine. Anesth Analg 2000; 90: 1308-14.

29. Santos AC, DeArmas PI. Systemic toxicity of levobupivacaine, bupivacaine, and ropivacaine during continuous intravenous infusion to nonpregnant and pregnant ewes. Anesthesiology 2001; 95: 1256-64. 